\title{
Characterization and functional analysis of SIAH1 during skin and hair follicle development in the angora rabbit (Oryctolagus cuniculus)
}

Tong Zhou', Yang Chen ${ }^{1,2}$, Bohao Zhao ${ }^{1}$, Shuaishuai Hu ${ }^{1}$, Jiali Li', Ming Liu', Shuang Liang ${ }^{1}$, Zhiyuan Bao ${ }^{1}$ and Xinsheng $\mathrm{Wu}^{1,2^{*}}$

\begin{abstract}
Background: Seven in absentia homolog 1 (SIAH1) is an E3 ubiquitin ligase containing a RING-finger domain and a key regulator of normal development. Skin and hair follicle development is a complex and special process of morphogenesis involving multiple signaling pathways. SIAH1 is enriched in the Wnt signaling pathway and potentially related to hair follicle cycle and skin development. This study aims to provide evidence for the role of SIAH1 in skin and hair development.

Results: Full-length cloning and analysis of SIAH1 was conducted to better understand its function. Phylogenetically, the sequence of SIAH1 in the rabbit shares the greatest homology with Home sapiens, Pongo abelii and Mus mulatta. Based on the rabbit hair follicle synchronization model, we found that the expression level of SIAH1 in the regressive period of the rabbit hair cycle is significantly lower than in the active growth and rest periods. In addition, the mRNA expression levels of skin and hair follicle development-related genes changed significantly when SIAH1 was overexpressed and silenced. After SIAH1 overexpression, the expression levels of WNT2, LEF1 and FGF2 decreased, and those of SFRP2 and DKK1 increased $(P<0.05)$. After interference of SIAH1, the expression levels of WNT2, LEF1 and FGF2 increased $(P<0.05)$, and SFRP2 and DKK1 decreased.

Conclusions: SIAH1 can affect skin and hair follicle development and exert an inhibitory effect. These results could provide foundamental insights into the role of SIAH1 as a target gene in rabbit skin and hair follicle development.
\end{abstract}

Keywords: SIAH1, Molecular cloning, Expression analysis, Skin and hair follicle development, Angora rabbit

\section{Background}

Skin and hair follicle development is a complex and special morphogenic process in which multiple signaling pathways and epithelial-mesenchymal interactions are involved [1]. Skin and hair follicle development is a cycling and self-renewal process, consisting of three periods:

\footnotetext{
* Correspondence: xswu@yzu.edu.cn

${ }^{1}$ College of Animal Science and Technology, Yangzhou University, Yangzhou, China

${ }^{2}$ Joint International Research Laboratory of Agriculture and Agri-Product Safety, Yangzhou University, Yangzhou, China
}

active growth (anagen), regression (catagen) then rest (telogen) [2, 3]. Dermal papilla (DP) cells are located at the base of the hair follicle and secrete a variety of cytokines that regulate adjacent tissues, thereby regulating hair growth and renewal $[4,5]$. Dermal hair papilla cells can be used as a cell model to study hair follicle growth and periodic changes. A number of studies have revealed that different genes have either a promoting or inhibitory effect on skin and hair follicle development, including hepatocyte growth factor (HGF), heat shock protein

(c) The Author(s). 2020 Open Access This article is licensed under a Creative Commons Attribution 4.0 International License, which permits use, sharing, adaptation, distribution and reproduction in any medium or format, as long as you give appropriate credit to the original author(s) and the source, provide a link to the Creative Commons licence, and indicate if changes were made. The images or other third party material in this article are included in the article's Creative Commons licence, unless indicated otherwise in a credit line to the material. If material is not included in the article's Creative Commons licence and your intended use is not permitted by statutory regulation or exceeds the permitted use, you will need to obtain permission directly from the copyright holder. To view a copy of this licence, visit http://creativecommons.org/licenses/by/4.0/. The Creative Commons Public Domain Dedication waiver (http://creativecommons.org/publicdomain/zero/1.0/) applies to the data made available in this article, unless otherwise stated in a credit line to the data. 
27 (HSP27), secreted frizzled-related protein 4 (SFRP2) and fibroblast growth factor 5 (FGF5) [6-9]. Previously, differentially expressed genes (DEGs) related to hair follicle cycling were identified by Illumina sequencing in skin samples from different stages of skin and hair follicle developmental in Angora rabbits, including $B M P 2$, KRT17, HTATIP2 and SIAH1 [10].

Although multiple genes that are possibly implicated in the skin and hair development have been identified, the specific role of SIAH1 in this respect remains unclear. SIAH1 is an E3 ubiquitin ligase containing a RING-finger domain and a key regulator of normal development. SIAH1 functions by degrading substrate proteins using the polyubiquitin-proteasome pathway [11]. The Wnt signaling pathway plays an important role in the regulation of skin and hair follicle development, by regulating the hair growth cycle and promoting hair follicle differentiation [12]. SIAH1 affects the activation of the $\beta$-catenindependent $\mathrm{T}$ cell factor/lymphocyte enhancer (TCF/LEF) family of transcription factors by modifying the quantity of $\beta$-catenin that is deposited in the nucleus, thereby regulating cell proliferation [13-15]. SIAH1 displays a variety of cell biological functions, participating in cell cycle regulation, and cellular differentiation and apoptosis [16-18]. In our early studies, we found significant differences in SIAH1 expression in rabbits at different stages of hair follicle cycle, suggesting that the SIAH1 may be involved in the periodic growth of hair follicles [10].

In this study, the complete coding sequence (CDS) of SIAH1 of Angora rabbits was amplified. The sequence characteristics and evolutionary relationship of SIAH1 were predicted using bioinformatics analysis. In addition, mRNA expression levels of this gene from various tissues were examined at different phases of hair growth. Furthermore, interference and overexpression techniques were utilized to promote and inhibit SIAH1 mRNA expression levels which, with other genes involved in skin and hair follicle development, were examined in rabbit dermal papilla cells. The results provide evidence for the role of SIAH1 in skin and hair development.

\section{Results}

\section{CDNA cloning and sequence analysis of SIAH1}

The full length of the cloned SIAH1 (GenBank accession no. MN520291) was $1715 \mathrm{bp}$, of which the $5^{\prime}$-untranslated region (UTR) was $188 \mathrm{bp}$ and the $3^{\prime}$-UTR $579 \mathrm{bp}$. The open reading frame (ORF) had a length of $948 \mathrm{bp}$ and encoded 315 amino acids (Fig. 1a). The analysis indicated that the CDS of SIAH1 contained RING structural (residues 74-108) and Sina (residues 115-311) domains.

The isoelectric point (PI) and peptide molecular weight predicted by the ProtParam tool were 6.40 and
$34.9 \mathrm{kDa}$. The SIAH1 amino acid sequence had 29 residues with a negative charge and 26 with a positive charge suggesting that the protein as a whole possessed a negative charge. The instability coefficient was estimated to be 46.92, indicating that this protein was classified as an unstable protein. The hydrophobicity analysis indicated that SIAH1 was a hydrophilic protein. According to the results of SignalP 5.0 software analysis, the protein possessed no apparent signaling peptide. TMHMM prediction software demonstrated no significant transmembrane protein domain, indicating that SIAH1 was neither a membrane receptor nor a membrane. SIAH1 was shown to be principally distributed in the nucleus $(47.8 \%)$ and secondarily within the cytoplasm (34.8\%), indicating that SIAH1 performs its biological role mainly in the nucleus. The predicted secondary structure was shown to be $21.59 \%$-helix, $51.75 \%$ random coil, $20.63 \%$ extended strand and $6.03 \%$ beta turn.

\section{Multiple sequence alignment and evolutionary relationships of SIAH1}

The sequence of the rabbit SIAH1 coding region obtained from NCBI was aligned with the multiple amino acid (AA) sequences of SIAH1 from other species using the online tool Blastp. The AA sequences of SIAH1 were 99.65-97.18\% identical with Mus musculus (XP_ 006530847), Rattus norvegicus (NP_543181), Bos Taurus (XP_005218736), Gallus gallus (XP_015147905), Equus caballus (XP_023492691), Xenopus laevis (NP 001085438), Pongo abelii (XP_002826444), Macaca mulatta (NP_001247767), Home sapiens (NP_001006611), Ovis aries (XP_004015022) and Danio rerio (NP_955815). The two conserved domains of SIAH1 were also found in identical positions, demonstrating that they were highly conserved among different species. The sequence of SIAH1 in rabbits was identical to Home sapiens, Pongo abelii and Mus mulatta, except for the 32 AA N-terminal end of the sequence (Fig. 1b).

NJ-phylogenetic trees were constructed using SIAH1 sequences from rabbits and multiple other species. The amino acid sequence of rabbit SIAH1 possessed the greatest homology with Home sapiens, Pongo abelii and Mus mulatta and the lowest with Danio rerio (Fig. 1c).

\section{Expression profile of SIAH1 in different tissues and hair follicle cycle}

Tissue distribution can provide useful insights into putative gene function. The expression of SIAH1 mRNA was observed in all tissues examined with differential expression. The highest expression levels of SIAH1 mRNA were detected in the lung, spleen, dorsal skin and kidney, with a moderate level of expression detected in the 
(a)



(c)

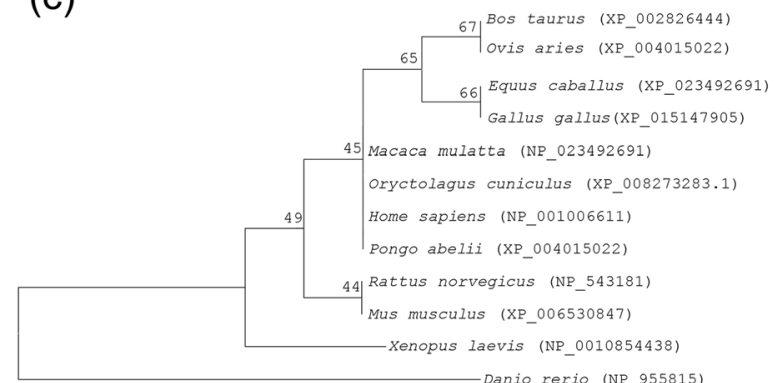

(b)
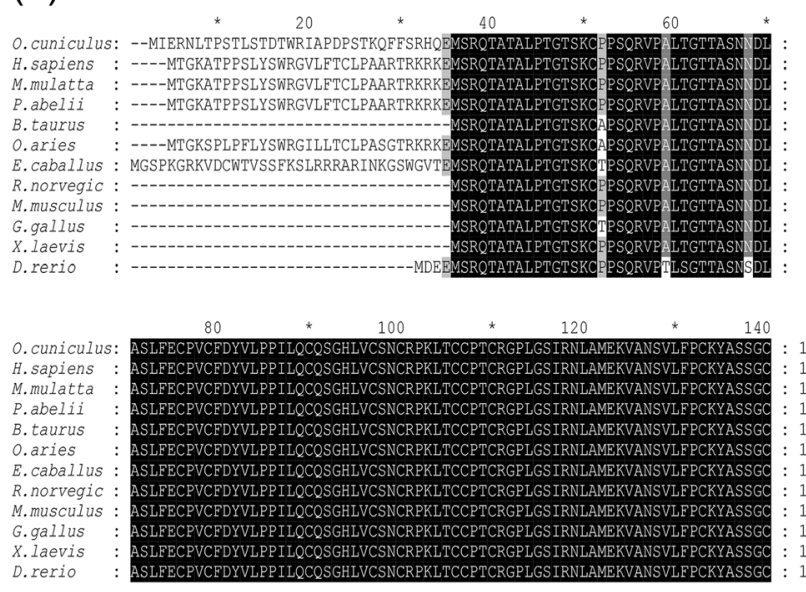

$: 138$
$: 136$
$: 136$
$: 136$
$: 105$
$: 136$
$: 140$
$: 105$
$: 105$
$: 105$
$: 105$
$: 109$

O.cuniculus:

H. sapiens

M.mulatta

P.abelii

B.taurus

E.caballus:

R.norvegic:

M.musculus:

G.gallus

$X$. laevis

D. rerio

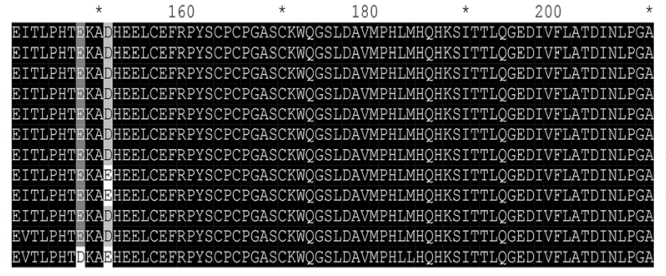

208
206
206
206
1175
206
210
1175
$: 175$
175
$: 175$
$: 179$

O.cuniculus:
H. sapiens

H. sapiens :

M. mulatt

P. abeli

O.aries

E.caballus

R.norvegic

M. musculus:

X.laevis

D.rerio

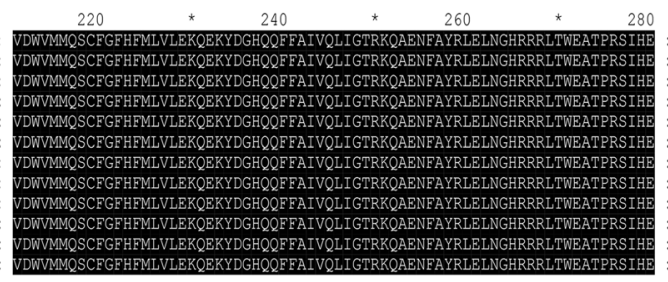

$: 278$
$: 276$
$: 276$
$: 276$
$: 245$
$: 276$
$: 280$
$: 245$
$: 245$
$: 245$
$: 245$
$: 249$

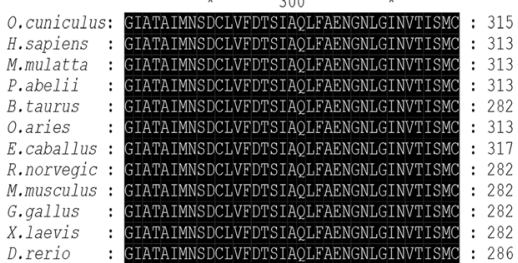

0.002

Fig. 1 Molecular characterization of SIAH1. a Nucleotide and deduced amino acid sequences of Angora rabbit SIAH1 gene. * indicates stop codon; blue letters indicate initiation codon; green letters indicate termination codon; the RING domain is in bold and the Sina domain underlined. b Multiple sequence alignment of deduced amino acids of SIAH1 between rabbit and other species. The black and gray highlights represent identical and similar, respectively. c The neighbor-joining phylogenetic tree was constructed based on the SIAH1 amino acid sequence of each species. The confidence of each node was evaluated repeatedly by 1000 bootstrap with Mega 7.0. The ruler (0.002) means

genetic distance

intestine, liver and stomach, while the least expression was observed in the brain, heart and leg muscles (Fig. 2a).

mRNA levels of SIAH1 at were measured at 9 time points in the skin development and hair follicle cycle of the rabbit. These time points were selected based on the cycle of rabbit hair follicles, including anagen, catagen and telogen stages. Based on the rabbit hair follicle synchronization model, we found that the expression level of SIAH1 in the regressive period of the rabbit hair cycle was significantly lower than that in the active growth and rest periods (Fig. $2 \mathrm{~b}$ ).

\section{Detection of SIAH1 mRNA expression after its overexpression and interference}

In order to analyze the functions of SIAH1, three specific siRNAs were created and a pcDNA3.1-SIAH1 overexpression vector established. By preparing nucleic acid- 


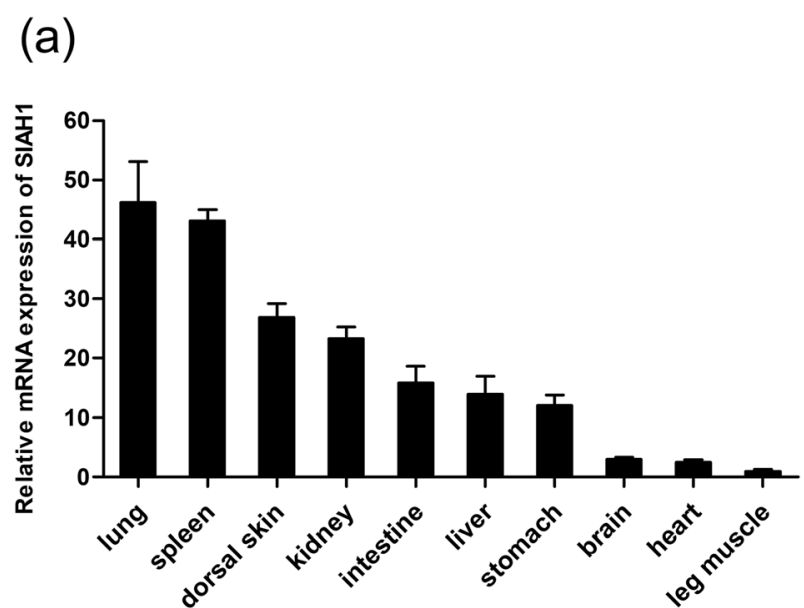

(b)

Fig. 2 Relative expression levels of SIAH1 in various tissues and hair follicle cycle. a Real-time RT-PCR was used to measure mRNA levels of SIAH1 in different tissues. The data represent means \pm SD $(n=9)$. Expression levels in the leg muscle were set to 1.0. $\mathbf{b}$ Relative expression levels of Angora rabbit SIAH1 during hair cycling in the dorsal skin. Data represent means \pm SD $(n=9)$. Expression level at day 0 was set to 1.0

liposome complexes, pcDNA3.1-SIAH1 and three siRNAs were transfected into DP cells and the expression of SIAH1 quantified by qRT-PCR. Quantitative RT-PCR analysis using GAPDH as the endogenous control indicated that all three siRNAs reduced the expression of SIAH1 mRNA but exhibited a different degree of interference compared with the siRNA-NC control group (Fig. 3a).

By comparing SIAH1 mRNA levels in different siRNA groups, it was found that siRNA-3 had the greatest inhibitory effect on SIAH1 mRNA expression levels, levels which were significantly lower than those of the siRNA-
NC group, with inhibition ratios of $65.63,82.98$ and $87.23 \%$, respectively (Table 1 ). In addition, we observed that the SIAH1 mRNA expression levels in the pcDNA3.1-SIAH1 group were significantly higher than those in the pcDNA3.1 group (Fig. 3b).

\section{Expression of skin and hair follicle development-related} genes following overexpression and interference of SIAH1 The pcDNA3.1-SIAH1 vector and siRNA-2 with the highest inhibition ratio of SIAH1 mRNA expression levels were transfected into DP cells, and the expression levels of skin and hair follicle development-related genes

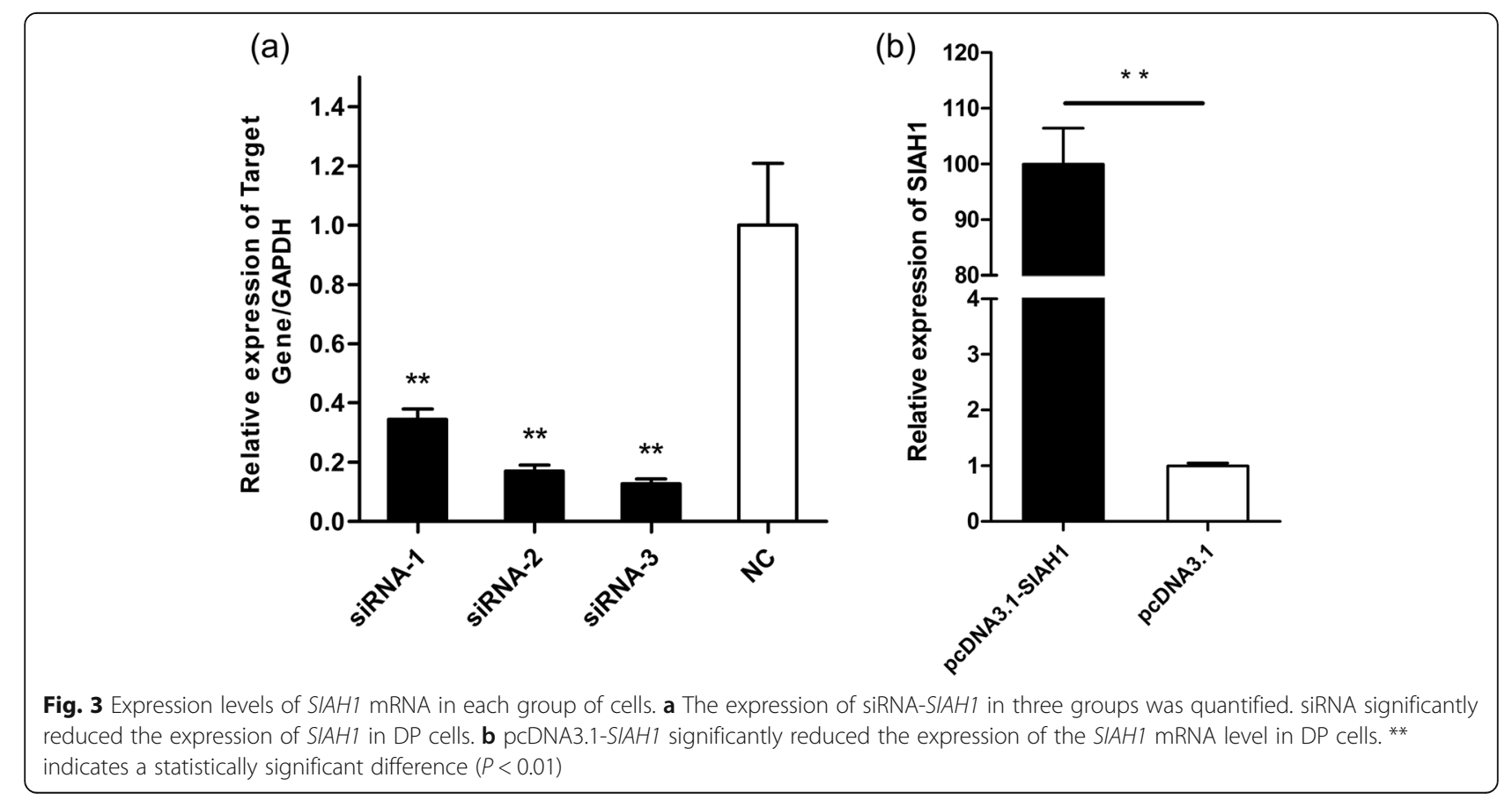


Table 1 Expression levels of SIAH1 mRNA in different siRNA groups

\begin{tabular}{lllll}
\hline Group & $\Delta \mathrm{Ct}$ & $\Delta \Delta \mathrm{Ct}$ & Relative expression & Inhibition Ratio (\%) \\
\hline siRNA-1 & $8.94 \pm 0.15$ & $1.52 \pm 0.15$ & $0.34^{\mathrm{c}}$ & $65.63 \%$ \\
siRNA-2 & $9.95 \pm 0.16$ & $2.54 \pm 0.16$ & $0.17^{\mathrm{b}}$ & $82.98 \%$ \\
siRNA-3 & $10.37 \pm 0.17$ & $2.96 \pm 0.17$ & $0.13^{\mathrm{a}}$ & $87.23 \%$ \\
siRNA-NC & $7.41 \pm 0.26$ & $0.00 \pm 0.26$ & $1.00^{\mathrm{d}}$ & - \\
\hline
\end{tabular}

Values with the same lower case letter indicate no significant difference $(P>0.05)$. Different letters indicate significant differences $(P<0.05)$. CT cycle threshold, mRNA messenger RNA, siRNA small interfering RNA

WNT2, LEF1, FGF2, SFRP2 and DKK1 quantified by qRT-PCR. The expression levels of these five genes changed significantly when SIAH1 was overexpressed, with WNT2, LEF1 and FGF2 expression levels decreased and those of SFRP2 and DKK1 increased $(P<0.01)$ (Fig. 4a). Conversely, siRNA-SIAH1 caused a significant increase in the expression levels of WNT2, LEF1 and $F G F 2$, with a significant decrease in expression levels of SFRP2 and DKK1 $(P<0.01)$ (Fig. 4b).

\section{Discussion}

Genetic factors play a major role in determining traits in rabbit fur. Exploring the molecular mechanisms regulating skin and hair follicle development is currently a topic of considerable attention in medical and biological research $[19,20]$. A previous study found that SIAH1 was enriched in the Wnt signaling pathway and potentially related to hair follicle cycle and skin development [10]. Many studies have confirmed that SIAH1 overexpression in cells decreases the expression of $\beta$-catenin through $\beta$ catenin degradation-dependent and independent mechanisms $[14,21,22]$. $\beta$-catenin is involved in the proliferation and differentiation of hair follicle stem cells and other biological regulation processes associated with skin and hair follicle development [23-25]. However, there is insufficient research evidence about the role of SIAH1 in hair follicle cycling.

In the present study, we cloned and characterized the full-length of the cDNA sequence of SIAH1 which was found to include a $188 \mathrm{bp} 5^{\prime}$-UTR, an ORF of $948 \mathrm{bp}$ and a 579 bp $3{ }^{\prime}$-UTR. The predicted SIAH1 amino acid sequence was found to contain a conserved protein domain family, of the Seven in absentia (Sina) superfamily. Like its Drosophila Sina homologue, mammalian SIAH1 interacts with its target protein using the C-terminal substrate binding domain and labels it with ubiquitin. The protein complex then binds to the E2 protein via the N-terminal RING domain of SIAH1 leading finally to degradation of the substrate protein through the ubiquitin-proteasome degradation pathway [26-28]. Except for differences in length and sequence of the $32 \mathrm{AA}$ $\mathrm{N}$-terminal end of SIAH1 in different animals, the sequence in rabbits is highly conserved compared with other animals. The conserved sequence of SIAH1 contains two major functional domains, indicating that the role of SIAH1 may be stable across different species. Phylogenetic tree analysis again revealed that the sequence possessed close genetic relationships with these.

SIAH1 mRNA was found to be widely expressed but at different levels in all tissues examined in our study.




Wide differences in levels of SIAH1 mRNA expression have also been observed in a range of adult and mouse tissues [29, 30]. Studies have found that SIAH1 is also widely present in many cell lines and human tissues [31]. The extensive tissue distribution of SIAH1 suggests that it may play an important cellular role. However, the high levels of SIAH1 in dorsal skin suggests that it may have a genetic function in those sites. According to relevant research, the anagen, catagen and telogen phases of Angora rabbit hair after shaving occur at $0-110,120$ 130 and 140-150 days, respectively [10]. Skin and hair follicle development-related genes play different roles at the various stages of hair follicle development. For example, SFRP2 is principally expressed during the degenerative phase [8]. DDK1 is an inhibitor of the classical Wnt signaling pathway and is mainly expressed during the growth phase [32]. WNT2, LEF1 and FGF2 are principally expressed during growth or degenerative phases [33-35]. In the present study, the mRNA expression levels of SIAH1 were found to be significantly lower in the degenerative phase than in the growing and resting phases. Quantification of the expression of skin and hair follicle development-related genes indicated that there was a significant relationship between SIAH1 and the other related genes. These may explain why SIAH1 is mainly expressed in the growth and resting phases, and also suggests that SIAH1 does not play an important role in the degenerative phase of hair follicles.

In order to explore whether SIAH1 promotes or plays an inhibitory role in the hair cycling of the rabbit, several skin and hair follicle development-related genes were selected for functional verification. WNT2 plays an important role in regulating hair length in hair follicle morphogenesis and may be important for hair follicle initiation [33, 36]. LEF1 mediates cell division and migration by mediating Wnt signaling by binding to $\beta$ catenin [34]. FGF2 promotes the proliferation of dermal papillae and mitosis of true skin fibroblasts [35]. During catagen of hair follicles, SFRP2 affects skin and hair follicle development by inhibition of keratinocyte proliferation and Wnt activity [8] and DKK1 has been shown to promote the regression of hair follicles [37]. The expression levels of all these genes changed significantly after overexpression of SIAH1. However, this change showed two trends: the expression levels of WNT2, LEF1 and FGF2 decreased, but those of SFRP2 and DKK1 increased. After inhibition of SIAH1 expression, the expression levels of those genes exhibited a change that was opposite. Therefore, we believe that SIAH1 inhibits the skin development and hair follicle cycle.

\section{Conclusions}

In conclusion, we successfully amplified the complete SIAH1 sequence based on the existing predicted sequences and analyzed the structure, identity and phylogeny of the amino acid sequence. The expression of SIAH1 in hair cycling and in different tissues was examined, revealing that SIAH1 is highly expressed in the lung, spleen, dorsal skin and kidneys, with expression levels of SIAH1 in the regressive period significantly lower than that in the active growth and rest periods. Measurement of the expression levels of other skin and hair follicle development-related genes after overexpression and interference of SIAH1 mRNA revealed that the gene can affect skin and hair follicle development and exert an inhibitory effect. These results could provide foundamental insights into the role of SIAH1 as a target gene in rabbit skin and hair follicle development.

\section{Materials and methods}

\section{Animals and sample collection}

The Anhui Academy of Agricultural Sciences provided 6-month-old male Wanxi Angora rabbits. All animal procedures were approved by the Animal Care and Use Committee of Yangzhou University. The hair on the back of each rabbit was shaved using an electric shaver until the light pink skin was exposed, causing the structure of the hair follicles to be destroyed and resulting in them starting a complete hair follicle cycle. The experimental Angora rabbits were housed in an appropriate, clean and disease-free environment and had free access to water and pellet feed. The temperature and relative humidity were regulated to $15-25^{\circ} \mathrm{C}$ and $40-60 \%$, respectively. Rabbit health was monitored and recorded twice daily (7:00 and 18:00). Rabbits were sacrificed with intravenous injection of air. One $\mathrm{cm}^{2}$ of skin on the back of each experimental rabbit was harvested into a sample tube and placed quickly in liquid nitrogen, at days 0,30 , $60,100,110,120,130,140$ and 150. In addition, samples of the heart, liver, spleen, lung, kidney, brain, stomach, small intestine, dorsal skin and leg muscle were collected from three healthy rabbits at 180 days of age. Similarly, these samples of tissue were quickly placed in liquid nitrogen to prevent RNA degradation, then stored in a $80^{\circ} \mathrm{C}$ freezer for total RNA extraction.

\section{Full-length acquisition of SIAH1}

The full length of the SIAH1 gene was obtained using three $5^{\prime}$-RACE primers (GSP1, GSP2 and GSP3) and two 3'-RACE primers (C396-1 and C396-2) that were designed by reference to the amplified CDS sequence. The $5^{\prime}$ and $3^{\prime}$ end sequences were amplified using a SMARTer $^{\text {Tx }}$ RACE cDNA Amplification kit (Clontech, China) in accordance with the manufacturer's instructions. The amplified product was subjected to electrophoresis and the target band purified. After purification, the product was ligated to a $\mathrm{pMD}-19 \mathrm{~T}$ vector, then the 
positive clone selected for sequencing. Sequences of the primers are displayed in Table 2.

\section{Sequence analysis of SIAH1}

Sequence analysis of the Angora rabbit SIAH1 was performed by ExPaSy software (https://web.expasy.org/protparam/) [38]. Protein sequence alignments were performed using Clustal (https://www.ch.embnet.org/) [39]. A phylogenetic tree was constructed using MEGA 7.0 software [40] Kumar using the neighbor-joining method. Structural domains were predicted using SMART (http://smart.embl-heidelberg.de/) [41] and the secondary structure of the protein predicted using the online software SOPMA (https://prabi.ibcp.fr/htm/site/ web/) [42]. Protein signal peptides were predicted using SignalP 4.1 (http://www.cbs.dtu.dk/services/SignalP-4.1/) [43]. Protein transmembrane domains were predicted by TMHMM (http://www.cbs.dtu.dk/services/TMHMM/) [44]. Predictive analysis of subcellular localization of the SIAH1 was conducted using PSORT II Prediction (https://psort.hgc.jp/form2.html) [45].

\section{Cell culture and transfection}

Dermal papilla cell lines that were established by our research group were used to consuct cell experiments. DP cells were cultured in mesenchymal stem cell medium $\left(\right.$ ScienCell $\left.{ }^{\circ}\right)$ containing 5\% fetal bovine serum, 1\% mesenchymal stem cell growth supplement and 1\% penicillin/streptomycin solution. The cells were cultured in an incubator at $37^{\circ} \mathrm{C}$ within an atmosphere containing $5 \%$ $\mathrm{CO}_{2}$ and a high relative saturation humidity (95\%). The DP cells were seeded into 24-well cell culture plates then transfected with Lipofectamine ${ }^{\text {Tm }} 3000$ (Invitrogen, CA) when $80 \%$ confluent, in accordance with the manufacturer's recommended protocol.

\section{Quantitative real-time polymerase chain reaction}

Total RNA was extracted from the cultured cells and skin and tissue samples using an RNA extraction kit (Tiangen, China). Approximately $1 \mu \mathrm{g}$ of total RNA was synthesized into complete cDNA for qRT-PCR using HiScript reverse transcriptase (Vazyme, China). The reverse transcription reaction contained $1 \mu \mathrm{g}$ of total RNA and $4 \mu \mathrm{L}$ of $4 \times$ gDNA wiper mix supplemented with

Table 2 Primers used for RACE

\begin{tabular}{lll}
\hline Name & Sequences of primers (5'-3') & Application \\
\hline GSP1 & TCTGCTGAAGAACTGC & 5'-RACE \\
GSP2 & TCAGGGGCAATCCTCCAC & 5'-RACE \\
GSP3 & GAGAGTGTACTAGGAGTCAAG & 5'-RACE \\
C396-1 & ATGGGCACAGGCGACGATTGACTT & 3'-RACE \\
C396-2 & GAGGGAATTGCGACAGCCATCATG & 3'-RACE \\
\hline
\end{tabular}

$\mathrm{ddH}_{2} \mathrm{O}$ to $16 \mu \mathrm{L}$. The first step reaction mixture was incubated at $42^{\circ} \mathrm{C}$ for $2 \mathrm{~min}$, then $4 \mu \mathrm{L}$ of $5 \times \mathrm{qRT}$ SuperMix were added to the $16 \mu \mathrm{L}$ mixture which was incubated at $50^{\circ} \mathrm{C}$ for $15 \mathrm{~min}$ then $85^{\circ} \mathrm{C}$ for $3 \mathrm{~min}$ to synthesize cDNA. The template DNA was analyzed using qRT-PCR with ChamQ $^{\text {ma }}$ SYBR $^{\circ}$ qPCR Master Mix (Vazyme). The $20 \mu \mathrm{L}$ PCR reaction included $10.0 \mu \mathrm{L} 2 \times$ ChamQ SYBR qPCR Master Mix, $0.4 \mu \mathrm{L}$ of each specific forward and reverse primer $(10 \mu \mathrm{M}), 0.4 \mu \mathrm{L}$ of $50 \times \mathrm{ROX}$ Reference Dye $2,1.0 \mu \mathrm{L}$ of cDNA and $7.8 \mu \mathrm{L}$ of $\mathrm{dd}_{2} \mathrm{O}$. The data were processed using a QuantStudio $^{\circ} 5$ realtime PCR system (Applied Biosystems). The $2^{-\Delta \Delta C t}$ method [46] was used to calculate the relative expression levels of genes, the resulting data normalized against the endogenous control glyceraldehyde-3-phosphate dehydrogenase $(G A P D H)$. All primers were designed using Primer Premier 5.0 software and synthesized by Tsingke Biological Company (Beijing, China) (Table 3).

\section{Overexpression and interference of SIAH1}

First strand cDNA was synthesized from the total RNA from $1 \mu \mathrm{g}$ of high-quality rabbit skin using a HiScript ${ }^{\circ}$ II1st Strand cDNA Synthesis Kit (Vazyme). Primers were designed from the rabbit SIAH1 CDS sequence (GenBank accession no. XM_008275061.2). The $50 \mu \mathrm{L}$ PCR reaction mixture contained $1 \mu \mathrm{L}$ cDNA, $2 \mu \mathrm{L}$ forward primer $(10 \mu \mathrm{M}), 2 \mu \mathrm{L}$ reverse primer $(10 \mu \mathrm{M}), 1 \mu \mathrm{L}$ Phanta Max Super-Fidelity DNA Polymerase, $1 \mu \mathrm{L}$ dNTP Mix, $25 \mu \mathrm{L}$ Phanta Max Buffer and $18 \mu \mathrm{L} \mathrm{dd}_{2} \mathrm{O}$. The PCR product was identified using a $1.5 \%$ agarose gel and the specific fragment recovered and purified using an agarose gel DNA extraction kit (TaKaRa, China). The SIAH1 CDS sequence was subcloned into HindIII and EcoRI digested pcDNA 3.1 vector (Invitrogen), which was termed pcDNA3.1-SIAH1. The siRNA-SIAH1 and

Table 3 Primer sequences for qRT-PCR

\begin{tabular}{ll}
\hline Name & Sequences of primers (5'-3') \\
\hline GAPDH & F: CACCAGGGCTGCTITAACTCT \\
& R: CTTCCCGTCTCAGCCTTGACC \\
SIAH1 & F: ACGACCGCGTCCAACAATGA \\
& R: AGCTTGGGCGACAGTTGCT \\
WNT2 & F: AGCCATCCAGGTCGTCATGAACCAG \\
& R: TGCACACACGACCTGCTGTACCC \\
LEF1 & F: CATCTCGGGTGGTTCAGG \\
& R: ATGAGGGATGCCAGTTGTG \\
FGF2 & F: GTGTGTGCAAACCGTACCTT \\
& R: TCGTTTCAGTGCCACATACCAG \\
SFRP2 & F: CCAGCCCGACTTCTCCTACAAGC \\
& R: TCCAGCACCTCTTCATGGTCT \\
DKK1 & F: CACAGAGGACGAGGAGTGTG \\
& R: CTTCCTGCAAGCCAGACAGA
\end{tabular}

$F$ forward primer, $R$ reverse primer 
Table 4 SIAH1 overexpression and interference related primer sequences

\begin{tabular}{ll}
\hline Name & Sequences of primers (5'-3') \\
\hline SIAH1 CDS & F: CCCAAGCTTATGATAGAAAGAAACTGACTCCTA \\
s: CCGGAATTCTCAACACATGGAATCGTTACATTG & F:GCACGACCGCGUCCAACAATT \\
R:UUGUUGGACGCGGUCGUGCTT & F:CCUCGUCUGGAUGUGAAAUTT \\
siRNA-2 & R:AUUUCACAUCCAGACGAGGTT \\
siRNA-3 & F:CCAGCAGUUCUUUGCAAUUTT \\
& R:AAUUGCAAGAACUGCUGGTT \\
siRNA-NC & F:UUCUCCGAACGUGUCACGUTT \\
& R:ACGUGACACGUUCGGAGATT
\end{tabular}

Bases in italics and underlined represent the enzyme cutting site. $F$ forward primer, $R$ reverse primer

siRNA-NC were purchased from GenePharma (Shanghai, China). The siRNA sequence is detailed in Table 4.

\section{Statistical analysis}

Statistical analysis was performed using SPSS v21.0 software (IBM Corporation, Armonk, USA). All data were presented as means $\pm \mathrm{SD}$. Depending on the various experimental requirements, either a one-way analysis of variance or t-test was conducted to analyze the statistical significance of the experimental data, with $P<0.05$ considered the criterion for statistical significance.

\section{Abbreviations}

SIAH1: Seven in absentia homolog 1; mRNA: messenger RNA; siRNA: small interfering RNA; qRT-PCR: quantitative real-time polymerase chain reaction; RACE: Rapid amplification of cDNA ends; DP: Dermal papilla; CT: Cycle threshold; P: P value; SD: Standard deviation

\section{Acknowledgments}

We thank Dr. Naisu Yang for valuable advice on the manuscript.

\section{Author contributions}

TZ conducted the analysis and drafted the manuscript. TZ, BHZ and SSH collected and analyzed the data. ML, SL, ZYB and JLL carried out experiments. TZ, YC and XSW designed the study and finalized the manuscript. All authors read and approved the final manuscript.

\section{Funding}

This study was funded by the Modern Agricultural Industrial System Special Funding (No. CARS-43-A-1) and the National Key Research and Development Program of China (No. 2018YFD0502203).

\section{Availability of data and materials}

The authors declare that the data supporting the findings of this study are available within the articles.

\section{Ethics approval}

All animal procedures were approved by the Animal Care and Use Committee of Yangzhou University, and performed in accordance with the Regulations for the Administration of Affairs Concerning Experimental Animals (China, 1988)

\section{Consent for publication}

Not applicable.

\section{Competing interests}

The authors declare that they have no competing interests.
Received: 14 October 2019 Accepted: 24 March 2020

Published online: 06 April 2020

\section{References}

1. Hardy MH. The secret life of the hair follicle. Trends Genet. 1992;8:55-61. https://doi.org/10.1016/0168-9525(92)90350-d.

2. Paus R, Cotsarelis G. The biology of hair follicles. N Engl J Med. 1999;341: 491-7. https://doi.org/10.1056/NEJM199908123410706.

3. Oshima H, Rochat A, Kedzia C, Kobayashi K, Barrandon Y. Morphogenesis and renewal of hair follicles from adult multipotent stem cells. Cell. 2001; 104:233-45. https://doi.org/10.1016/s0092-8674(01)00208-2.

4. Jeong KH, Joo HJ, Kim JE, Park YM, Kang H. Effect of mycophenolic acid on proliferation of dermal papilla cells and induction of anagen hair follicles. Clin Exp Dermatol. 2015;40:894-902. https://doi.org/10.1111/ced.12650.

5. Morgan BA. The dermal papilla: an instructive niche for epithelial stem and progenitor cells in development and regeneration of the hair follicle. Cold Spring Harb Perspect Med. 2014;4:a015180. https://doi.org/10.1101/ cshperspect.a015180.

6. Adly MA, Assaf HA, Hussein MR. Expression of the heat shock protein-27 in the adult human scalp skin and hair follicle: hair cycle-dependent changes. J Am Acad Dermatol. 2006;54:811-7. https://doi.org/10.1016/j.jaad.2005.11.1097.

7. Higgins CA, Petukhova L, Harel S, Ho YY, Drill E, Shapiro L, Wajid M, Christiano AM. FGF5 is a crucial regulator of hair length in humans. Proc Natl Acad Sci U S A. 2014;111:10648-53. https://doi.org/10.1073/pnas. 1402862111.

8. Kim BK, Yoon SK. Expression of sfrp2 is increased in catagen of hair follicles and inhibits keratinocyte proliferation. Ann Dermatol. 2014;26:79-87. https:// doi.org/10.5021/ad.2014.26.1.79.

9. Qi Y, Li M, Xu L, Chang Z, Shu X, Zhou L. Therapeutic role of human hepatocyte growth factor (HGF) in treating hair loss. PeerJ. 2016;4:e2624. https://doi.org/10.7717/peerj.2624.

10. Zhao B, Chen Y, Hu S, Yang N, Wang M, Liu M, Li J, Xiao Y, Wu X. Systematic analysis of non-coding RNAs involved in the angora rabbit (Oryctolagus cuniculus) hair follicle cycle by RNA sequencing. Front Genet. 2019;10:407. https://doi.org/10.3389/fgene.2019.00407.

11. Hu G, Zhang S, Vidal M, Baer JL, Xu T, Fearon ER. Mammalian homologs of seven in absentia regulate DCC via the ubiquitin-proteasome pathway. Genes Dev. 1997;11:2701-14. https://doi.org/10.1101/gad.11.20.2701.

12. Lin C, Yuan Y, Chen X, Li H, Cai B, Liu Y, Zhang H, Li Y, Huang K. Expression of Wnt/ $\beta$-catenin signaling, stem-cell markers and proliferating cell markers in rat whisker hair follicles. J Mol Histol. 2015;46:233-40. https://doi.org/10. 1007/s10735-015-9616-5.

13. Matsuzawa SI, Reed JC. Siah-1, SIP, and Ebi collaborate in a novel pathway for beta-catenin degradation linked to p53 responses. Mol Cell. 2001;7:91526. https://doi.org/10.1016/S1097-2765(01)00242-8

14. Liu J, Stevens J, Rote CA, Yost HJ, Hu Y, Neufeld KL, White RL, Matsunami N. Siah-1 mediates a novel beta-catenin degradation pathway linking p53 to the adenomatous polyposis coli protein. Mol Cell. 2001;7:927-36. https://doi. org/10.1016/S1097-2765(01)00241-6.

15. Maeda A, Yoshida T, Kusuzaki K, Sakai T. The characterization of the human Siah-1 promoter. FEBS Lett. 2002;512:223-6. https://doi.org/10.1016/s00145793(02)02265-2.

16. Hara MR, Snyder SH. Nitric oxide-GAPDH-Siah: a novel cell death cascade. Cell Mol Neurobiol. 2006;26:527-38. https://doi.org/10.1007/s10571-0069011-6.

17. Jumpertz S, Hennes T, Asare Y, Vervoorts J, Bernhagen J, Schutz AK. The beta-catenin E3 ubiquitin ligase SIAH-1 is regulated by CSN5/JAB1 in CRC cells. Cell Signal. 2014;26:2051-9. https://doi.org/10.1016/j.cellsig.2014.05.013.

18. Li Q, Wang P, Ye K, Cai H. Central role of SIAH inhibition in DCC-dependent cardioprotection provoked by netrin-1/NO. Proc Natl Acad Sci U S A. 2015; 112:899-904. https://doi.org/10.1073/pnas.1420695112.

19. Sardella C, Winkler C, Quignodon L, Hardman JA, Toffoli B, Giordano Attianese GMP, Hundt JE, Michalik L, Vinson CR, Paus R, Desvergne B, Gilardi F. Delayed hair follicle morphogenesis and hair follicle dystrophy in a Lipoatrophy mouse model of Pparg Total deletion. J Invest Dermatol. 2018; 138:500-10. https://doi.org/10.1016/j.jid.2017.09.024.

20. Shirokova V, Biggs LC, Jussila M, Ohyama T, Groves AK, Mikkola ML. Foxi3 deficiency compromises hair follicle stem cell specification and activation. Stem Cells. 2016;34:1896-908. https://doi.org/10.1002/stem.2363.

21. Yoshibayashi H, Okabe H, Satoh S, Hida K, Kawashima K, Hamasu S, Nomura A, Hasegawa S, Ikai I, Sakai Y. SIAH1 causes growth arrest and apoptosis in 
hepatoma cells through beta-catenin degradation-dependent and -independent mechanisms. Oncol Rep. 2007;17:549-56. https://doi.org/10. 3892/or.17.3.549

22. Dimitrova YN, Li J, Lee YT, Eateves JR, Freidman DB, Choi HJ, Weis WI, Wang CY, Chazin WJ. Direct ubiquitination of beta-catenin by Siah-1 and regulation by the exchange factor TBL1. J Biol Chem. 2010;285:13507-16. https://doi.org/10.1074/jbc.M109.049411.

23. Huelsken J, Vogel R, Erdmann B, Cotsarelis G, Birchmeier W. Beta-catenin controls hair follicle morphogenesis and stem cell differentiation in the skin. Cell. 2001;105:533-45. https://doi.org/10.1016/S0092-8674(01)00336-1.

24. Choi YS, Zhang Y, Xu M, Yang Y, Ito M, Peng T, Zheng C, Nagy A, Hadjantonakis AK, Lang RA, Cotsarelis G, Andl T, Morrisey EE, Millar SE. Distinct functions for Wnt/beta-catenin in hair follicle stem cell proliferation and survival and interfollicular epidermal homeostasis. Cell Stem Cell. 2013; 13:720-33. https://doi.org/10.1016/j.stem.2013.10.003.

25. Lo Celso C, Prowse DM, Watt FM. Transient activation of beta-catenin signalling in adult mouse epidermis is sufficient to induce new hair follicles but continuous activation is required to maintain hair follicle tumours. Development. 2004;131:1787-99. https://doi.org/10.1242/dev.01052.

26. Hu G, Fearon ER. Siah-1 N-terminal RING domain is required for proteolysis function, and C-terminal sequences regulate oligomerization and binding to target proteins. Mol Cell Biol. 1999;19:724-32. https://doi.org/10.1128/mcb. 19.1.724.

27. House CM, Frew IJ, Huang HL, Wiche G, Traficante N, Nice E, Catimel B, Bowtell DD. A binding motif for Siah ubiquitin ligase. Proc Natl Acad Sci U S A. 2003;100:3101-6. https://doi.org/10.1073/pnas.0534783100.

28. Santelli E, Leone M, Li C, Fukushima T, Preece NE, Olson AJ, Ely KR, Reed JC, Pellecchia M, Liddington RC, Matsuzawa S. Structural analysis of Siah1-Siahinteracting protein interactions and insights into the assembly of an E3 ligase multiprotein complex. J Biol Chem. 2005;280:34278-87. https://doi. org/10.1074/jbc.M506707200.

29. Hu G, Chung YL, Glover T, Valentine V, Look AT, Rearon ER. Characterization of human homologs of the Drosophila seven in absentia (sina) gene. Genomics. 1997:46:103-11. https://doi.org/10.1006/geno.1997.4997.

30. Della NG, Senior PV, Bowtell DD. Isolation and characterisation of murine homologues of the Drosophila seven in absentia gene (sina). Development. 1993:117:1333-43.

31. Bruzzoni-Giovanelli $H$, Fernandez P, Veiga L, Podgorniak MP, Powell DJ, Candeias MM, Mourah S, Calvo F, Marín M. Distinct expression patterns of the E3 ligase SIAH-1 and its partner kid/KIF22 in normal tissues and in the breast tumoral processes. J Exp Clin Cancer Res. 2010;29:10. https://doi.org/ 10.1186/1756-9966-29-10.

32. Andl T, Reddy S, Gaddapara T, Millar SE. Wnt signals are required for the initiation of hair follicle development. Dev Cell. 2002;2:643-53. https://doi. org/10.1016/s1534-5807(02)00167-3.

33. Nie Y, Li S, Zheng X, Chen W, Li X, Liu Z, Hu Y, Qiao H, Qi Q, Pei Q, Cai D, Yu M, Mou C. Transcriptome reveals long non-coding RNAs and mRNAs involved in primary wool follicle induction in carpet sheep fetal skin. Front Physiol. 2018:9:446. https://doi.org/10.3389/fphys.2018.00446.

34. Nusse R. Wnt signaling in disease and in development. Cell Res. 2005;15:2832. https://doi.org/10.1038/sj.cr.7290260.

35. Kiso M, Hamazaki TS, Itoh M, Kikuchi S, Nakagawa H, Okochi H. Synergistic effect of PDGF and FGF2 for cell proliferation and hair inductive activity in murine vibrissal dermal papilla in vitro. J Dermatol Sci. 2015;79:110-8. https://doi.org/10.1016/j.jdermsci.2015.04.007.

36. Yue Y, Guo T, Yuan C, Liu J, Guo J, Feng R, Niu C, Sun X, Yang B. Integrated analysis of the roles of long noncoding RNA and coding RNA expression in sheep (Ovis aries) skin during initiation of secondary hair follicle. PLoS One. 2016;11:e0156890. https://doi.org/10.1371/journal.pone.0156890.

37. Kwack MH, Kim MK, Kim JC, Sung YK. Dickkopf 1 promotes regression of hair follicles. J Invest Dermatol. 2012;132:1554-60. https://doi.org/10.1038/jid. 2012.24.

38. Artimo $P$, Jonnalagedda M, Arnold $K$, Baratin D, Csardi G, de Castro E, Duvaud S, Flegel V, Fortier A, Gasteiger E, Grosdidier A, Hernandez C, loannidis V, Kuznetsov D, Liechti R, Moretti S, Mostaguir K, Redaschi N, Rossier G, Xenarios I, Stockinger H. ExPASy: SIB bioinformatics resource portal. Nucleic Acids Res. 2012;40(W1):W597-603. https://doi.org/10.1093/ nar/gks400.

39. Larkin MA, Blackshields G, Brown NP, Chenna R, McGettigan PA, McWilliam $H$, Valentin F, Wallace IM, Wilm A, Lopez R, Thompson JD, Gibson TJ,
Higgins DG. Clustal W and Clustal X version 2.0. Bioinformatics. 2007;23: 2947-8. https://doi.org/10.1093/bioinformatics/btm404.

40. Kumar S, Stecher G, Tamura K. MEGA7: molecular evolutionary genetics analysis version 7.0 for bigger datasets. Mol Biol Evol. 2016;33:1870-4. https://doi.org/10.1093/molbev/msw054.

41. Letunic I, Bork P. 20 years of the SMART protein domain annotation resource. Nucleic Acids Res. 2018;46:D493-6. https://doi.org/10.1093/nar/ gkx922.

42. Geourjon C, Deleage G. SOPMA: significant improvements in protein secondary structure prediction by consensus prediction from multiple alignments. Comput Appl Biosci. 1995;11:681-4. https://doi.org/10.1042/ CS077029PC

43. Petersen TN, Brunak S, von Heijne G, Nielsen H. SignalP 4.0: discriminating signal peptides from transmembrane regions. Nat Methods. 2011;8:785-6. https://doi.org/10.1038/nmeth.1701.

44. Tatusov RL, Koonin EV, Lipman DJ. A genomic perspective on protein families. Science. 1997;278:631-7. https://doi.org/10.1126/science.278.5338.631.

45. Nakai $K$, Horton P. PSORT: a program for detecting sorting signals in proteins and predicting their subcellular localization. Trends Biochem Sci. 1999;24:34-6. https://doi.org/10.1016/S0968-0004(98)01336-X.

46. Schmittgen TD, Livak KJ. Analyzing real-time PCR data by the comparative CT method. Nat Protoc. 2008:3:1101-8. https://doi.org/10.1038/nprot.2008.73.

\section{Publisher's Note}

Springer Nature remains neutral with regard to jurisdictional claims in published maps and institutional affiliations.
Ready to submit your research? Choose BMC and benefit from:

- fast, convenient online submission

- thorough peer review by experienced researchers in your field

- rapid publication on acceptance

- support for research data, including large and complex data types

- gold Open Access which fosters wider collaboration and increased citations

- maximum visibility for your research: over $100 \mathrm{M}$ website views per year

At $\mathrm{BMC}$, research is always in progress.

Learn more biomedcentral.com/submissions 